\title{
A short study of effectiveness of Steroid injection for chronic plantar fasciitis
}

Authors

\section{Dr Vijendra Damor ${ }^{1}$, Dr Devendra Nayak ${ }^{2}$, Dr Deepak Singh Rajput ${ }^{3 *}$}

${ }^{1}$ Senior Resident, Department of Orthopaedics and Traumatology, Government Medical College Ratlam ${ }^{2}$ Associate Professor Department of Orthopaedics and Traumatology, Government Medical College Ratlam

${ }^{3}$ Senior Resident, Department of Orthopaedics and Traumatology, Government Medical College Ratlam *Corresponding Author

Dr Deepak Singh Rajput

58- Baapu nagar, Near Ratlam Public School, Ratlam, 457001, MP, India

\begin{abstract}
Aims and Objective: To assess clinical efficacy of steroid injection for treatment of chronic plantar fasciitis.

Design and Method: Study includes 50 patients with plantar fasciitis. In this study 25 patient treated by steroid injection $1 \mathrm{ml}(10 \mathrm{mg} / \mathrm{ml})$ and 25 patients with sterile distilled water randomly between age group (20yr to 60yr). Patients were evaluated as per visual analogue scale (VAS) scale at 1 month, 3 month and 6 month post injection.

Conclusion: The author concluded that In current single centre Randomised controlled study result indicate that treating chronic plantar fasciitis with steroid injection has the potential to reduce pain and improve the functional outcome.
\end{abstract}

\section{Introduction}

Plantar fasciitis is condition of pain and damage to tissue attached to the undersurface of calcaneus. It is a most common cause of heel pain accounts for total $11 \%$ to $15 \%$ of all foot problem that requires treatment ${ }^{1}$. Chronic plantar fasciitis commonly involves athelets ${ }^{1,2}$ and overweight in active middle aged individual ${ }^{1,3}$. Most of time plantar fasciitis is self limiting condition ${ }^{4}$. This condition occurs when the long fibrous fascia along the bottom of foot develops tears which cause pain and inflammation. Plantar fasciitis is a chronic degenerative process involving plantar fascia of foot most commonly at its attachment at calcaneus. Pathogenesis involves repetitive strain at foot that cause micro tearing and finally degenerative change. In histological analysis it is found marked thickening and fibrosis of plantar fascia along with collagen necrosis, chondroid metaplasia and calcification ${ }^{5,6}$. That's why this finding suggest it is a degenerative process and plantar fasciosis may be more accurate term ${ }^{5,7}$ Diagnosis of plantar fasciitis is primarily clinical only. Pain is most common symptom located inner part of the bottom of heel. Pain is worse at morning after awakening on first few steps or after long period of rest and it become lessens with the activity during day ${ }^{8}$. On clinical 
examination tenderness on medial aspect of heel and positive Windlass test i.e pain with passive dorsiflexion of the ankle and toe ${ }^{9}$.Treatment mainly remain conservative include activity modification, change of foot ware, NSAID, Braces and supports, physiotherapy include fascia stretching and strenthening, hot fomentation and rest this treatment provide significant result in initial stage of disease but in chronic cases result remain unsatisfactory. When conservative treatment become unsuccessful intralesionar steroid injection also remain good option for short term pain relief ${ }^{10,11,12}$. Platelet rich plasma therapy is a revolutionary new treatment that relieves pain by promoting long lasting healing of musculoskeletal coditions ${ }^{13,14}$.

\section{Material and Methods}

Reference population-patient reported in the Department of Orthopaedics, Traumatology and rehabilitation, Out Patient Department no 06 GMC Ratlam (M.P.) between the age group of 20-60 yr of both male and female with complain of heel pain for more than 4 month. When all conservative modalities fail. . Study performed between May 2018 to April 2019. Inclusion criteria included patient having heel pain for more than 4 month between age of 20-60yr both male and female, ability to walk, subject must understand the risk and benefit of the protocol and be able to give informed consent, availability for the duration of entire study period. Exclusion criteria included traumatic heel pain, heel pain less than 4 month, inflammatory disorder like gout, RA, ankylosing spondylosis etc, abnormal LFT and RFT, hematolgical disorders, diabetes, cancer, medically unfit patient, pregnant brest feeding or planning to become pregnant, compressive neuropathies, skin disorders, sever infection. Experimental population is numbered serially as $1,2,3$, up to 50 and divided in to two group, Group A with Odd no like 1,3,5 etc to 49 injected by steroid and Group B with even no like $2,4,6$ up to 50 they were treated by placebo injection. After painting and draping point of max tenderness located and is marked by dermi marker then local anesthesia is administrated after that dry needling (Pippering) done to stimulate the inflammatory response help in deeper penetration after this PRP was injected. After this sterile dress was applied at injection site. All patients were given maximum 3 day of NSAID.

With the start of treatment and with each follow up all patient were asked to rate their pain on VAS Score, with 0 indicating on pain and 10 indicating worst pain Further Roles and Maudsley ${ }^{16,17}$ score used to conclude outcome of study; excellent: no pain, patient satisfied with treatment outcome, unlimited walking without pain good: substantially decrease in symptom, patient satisfied with treatment, $1 \mathrm{hr}$ walking pain free. Acceptable: symptoms somewhat decreases, pain at more tolerable level, and patient slightly satisfied with treatment outcome. Poor: symptom identical or worse and patient not satisfied with treatment outcome. After study is completed, after decoding, the data will be collected, co-related and with standard statistical principles their 'p' value was calculated.

\section{Observation}

In this study we found that most of patient were in age group of (40-50yr)so incidence is higher among middle age individual (Table 1). Out of total 50 population our study show female preponderance that is $29(58 \%)$ female patient and $21(42 \%)$ were male patients (table 2). Incidence is higher among female.

Our study show reduction in VAS score at 1 month,3month and 6 month steroid show more significant pain relief as compare to placebo group. $(p<0.0001)$. (table 3$)$.We found that there was significant reduction of pain at 1 month, 3 month but at 6 month no significant difference in VAS score in both group.

\section{Result}

Sample of present study comprised of 50 patient with chronic plantar fasciitis. Of the total participants, $35(70 \%)$ were female and $15(30 \%)$ 
were male. Data were available for 25 patients in steroid group and 25 in placebo group at baseline, at 1 month, 3 month and 6 month.

Present study showed significant preponderance of middle aged (40-50yr) and most of them were female $56 \%$.

Among male people involved in heavy or active work like athelets, labour and police show preponderance in incidence than sedentary.
In each treatment group of plantar fasciitis female show significant higher score that male on base line VAS scale.

The score on VAS scale improve from base line in steroid group was significantly better that placebo group for pain relief at 1 month, 3 month, and but at 6 month there is insignificant difference in vas score .

Table 1 Age wise distribution og patient.

\begin{tabular}{|l|c|c|}
\hline Age in years & Frequency & Percent \% \\
\hline $21-30$ & 1 & 2 \\
\hline $31-40$ & 13 & 26 \\
\hline $41-50$ & 31 & 62 \\
\hline $51-60$ & 4 & 8 \\
\hline$>60$ & 3 & 6 \\
\hline Total & 140 & 100.0 \\
\hline
\end{tabular}

Table 2 Sex wise distribution of patient

\begin{tabular}{|l|c|c|}
\hline & Frequency & Percent \\
\hline F & 29 & $58 \%$ \\
\hline M & 21 & $42 \%$ \\
\hline Total & 140 & 100.0 \\
\hline
\end{tabular}

Table 3 VAS Score of patient at follow up.

\begin{tabular}{|l|c|c|c|c|c|c|}
\hline \multirow{2}{*}{ PRP/Steroid } & \multicolumn{2}{|c|}{ Steroid } & \multicolumn{2}{c|}{ placebo } & & \\
\cline { 2 - 7 } & Mean & $\pm \mathrm{Sd}$ & Mean & $\pm \mathrm{Sd}$ & $\mathrm{p}$ value & significance \\
\hline VAS PRE INJECTION & 7.03 & .750 & 7.10 & .572 & $>0.05$ & not significant \\
\hline VAS 1MNT & 2.46 & .779 & 7.10 & .742 & $<0.05$ & significant \\
\hline VAS 3MNT & 4.46 & .856 & 6.09 & .905 & $<0.05$ & significant \\
\hline VAS 6MNT & 6.12 & .495 & 6.02 & .681 & $>0.05$ & Not significant \\
\hline
\end{tabular}

\section{Discussion}

In our study 50 patients were selected with 25 patients each in each group. The VAS score in each of the groups were assessed individually at the end 1 month, 3 months and 6 months study; we found that there was significant decrease in pain in steroid group at 1 month, 3 month but at 6 month there is no significant difference in pain relief in both group.

When the VAS scores in the corticosteroid group were compared between 1 month and 3 months and 6 months we observed that there was a decrease in pain as the time progressed in corticosteroid group but not in placebo group, but at the end of 6 month VAS score of both group was similar.
Similarly, there was increase in the function of the patient as the time progressed in corticosteroid group compared to placebo group. VAS was better in the corticosteroid group with statistical significance.

The shortcomings of the study is absence of a diagnostic tool like a USG scan or an MRI for the confirmation of the diagnosis and the changes noted after the injection which might have provided a better insight to the changes that occur in the plantar fascia and thus quantifying the need for the injection and also the post injection changes in the fascia and the absence of a control arm in this study. 


\section{Conclusion}

The present study show that steroid is effective for short term pain management for pain relief.

\section{Reference}

1. De maio M, Paine R, Mangine RE et all 1993 ct 16(10);1153-63.

2. Warren BL, Med Sci Sports Exerc 1984;16(1);60-63.

3. Martin RL, Irrgang JJ, Conti SF (1998) Outcome study of subjects with insertional plantar fasciitis. Foot Ankle Int 19:803-811.

4. Davis PF, Severud E, Baxter DE (1994) Painful heel syndrome: results of nonoperative treatment. Foot Ankle Int 15:531-535.

5. schepsis AA, leach RE, gorzyca J Clin orthop relat res 1991;266:185-196 PubMed.

6. Snider MP,Clancy WG et all Sport Med 1983;11(4):215-219 pub med.

7. Owen BD,Wolf JM ET all j AM Podiatr Med Assoc .2003;93(3)234-237 pubmed

8. Gill LH,J Am Acad Ortho Surg 1997;5(2)109-117 pub med.

9. Neufeld SK, Cerrato R J AM Ortho surg 2008;16(6)338-346.

10. Bordelon RC, Subcalcaneal pain, Clin Ortho Rela Res 1983;117;49-53.

11. Kane D, Greaney T, Bresnihan B,USG guided injection of Recalcitral plantar fasciitis Annals of Sheum ds 1998;57(6)383-4.

12. Tsai WC, Wang CL, Tang FT et al Arch phys Med Rehabil 2000;81(10);1461-21 doi 10;10531 amp 2009.01.008.

13. Mukesh tiwari et al.. DOI hppt://dx.doi.org/10.1016/j.jcot.2013.01.008

14. Peerboom et al BMC musculoskeletal disorder 2010
15. A Siebe De Boer, Duncan E BMJ DOI 10.1136/bmjopen-2016-012884 volume 7, issue 11.

16. Hanke M, schoellner C et al(2003) exracorpreal shock wavw therapy for plantar fasciitis; randomized controlled multicentre trial 327:75.

17. Roles NC, Maudsley RH (1972) Radial tunnel syndrome: resistant tennis elbow as a nerve entrapment. J Bone Joint Surg 54B:499- 508 .

hppt://www.biomedcentra.com/1471-

2474/11/69. 